\title{
Solving the European Productivity Puzzle
}

In recent years, advanced economies around the globe have experienced a pronounced slowdown in productivity growth. The causes of this so-called secular stagnation remain unclear. Some economists argue that we are simply measuring productivity improvements incorrectly and that the statistics are ignoring technological innovations. Others place the blame on the Great Recession, arguing that labour productivity took the hit in countries with flexible labour markets when GDP growth was constrained by globally deficient demand. Most economists agree that stagnant productivity is a legitimate concern, and given that productivity growth is the main driver of economic growth, it is essential to find remedies. Unfortunately, the current economic climate is characterised by a low potential for increased productivity growth, making it particularly difficult for Europe to achieve any progress in catching up with the higher productivity levels in the US. One potential source of improvement could be increased investment in intangible capital, which is positively linked to productivity growth. Finally, the most recent data indicate that after a decade of almost continuous slowdown, Europe's productivity performance is actually beginning to strengthen, in part due to the pro-cyclicality of productivity. If investment and business spending on digitisation persist, the uptick in labour productivity could translate into better total factor productivity growth, a measure of efficiency which identifies possible spillovers from new technologies and innovation.

\section{Is Europe's Productivity Glass Half Full or Half Empty?}

Bart van Ark, The Conference Board, New York, USA; and University of Groningen, Netherlands.

Klaas de Vries, The Conference Board Europe, Brussels, Belgium.

Kirsten Jäger, The Conference Board Europe, Brussels, Belgium.

\section{Productivity Growth and International Competitiveness: Does Intangible Capital Matter?}

Cecilia Jona-Lasinio, Italian National Institute of Statistics (Istat), Rome, Italy; and University LUISS Guido Carli, Rome, Italy. Valentina Meliciani, University LUISS Guido Carli, Rome, Italy.

\section{Productivity and the Great Recession}

Nicholas Oulton, London School of Economics and Political Science, UK; and National Institute of Economic and Social Research, London, UK.

The Productivity Puzzle: It's the Lack of Investment, Stupid!

Alexander Herzog-Stein, Macroeconomic Policy Institute (IMK), Dusseldorf, Germany.

Gustav A. Horn, Macroeconomic Policy Institute (IMK), Dusseldorf, Germany.

\section{Can European Productivity Make Progress?}

Davide Castellani, Henley Business School, University of Reading, UK.

Mariacristina Piva, Università Cattolica del Sacro Cuore, Piacenza, Italy.

Torben Schubert, Lund University, Sweden; and Fraunhofer Institute for Systems and Innovation Research ISI, Karlsruhe, Germany.

Marco Vivarelli, Università Cattolica del Sacro Cuore, Milan, Italy. 